\title{
The Features and Evolution of Cluster Supply Chain Network
}

\author{
Binghua He \\ Ningbo Institute of Technology, Zhejiang University, Ningbo, China \\ Email:hebinghua77@163.com
}

How to cite this paper: He, B.H. (2016) The Features and Evolution of Cluster Supply Chain Network. Open Journal of Business and Management, 4, 751-762. http://dx.doi.org/10.4236/ojbm.2016.44073

Received: September 10, 2016

Accepted: October 16, 2016

Published: October 19, 2016

Copyright $\odot 2016$ by author and Scientific Research Publishing Inc. This work is licensed under the Creative Commons Attribution International License (CC BY 4.0).

http://creativecommons.org/licenses/by/4.0/ (c) (i) Open Access

\begin{abstract}
Cluster supply chain (CSC) is a special kind of enterprise network with double feature of cluster and supply chain and is an important channel for enterprises close to the knowledge, resources, markets, and technologies. Cluster supply chain has special network structure and network relational which are different from general cluster and supply chain. In a particular industry cluster region, all kinds of enterprises and non-enterprise organizations around the core enterprises are connected to form local integration of supply chain through "trust and commitment" informal or formal contract. According to structural dimension and relational dimension of social network analysis theory, cluster supply chain network can be divided into four basic tie types: sparse-weak tie, intensive-weak tie, sparse-strong tie and intensive-strong tie. The study shows that intensive-strong tie network maybe appears negative effect of network innovation locked when developing to late, and eventually leads to cluster supply chain network disintegration and reconstruction.
\end{abstract}

\section{Keywords}

Cluster Supply Chain, Feature, Evolution, Network

\section{Introduction}

The typical enterprise network in the world mainly includes enterprise internal network, enterprise strategic alliance and industrial cluster. Industrial cluster is a geographic concentration of interconnected businesses, suppliers, and associated institutions in a particular field, linked by commonalities and complementarities [1]. The cluster also can be interpreted as: "Geographic concentrations of interconnected companies, specialized suppliers, services providers, firms in related industries, training institutions and support organizations linked around as technology or end product within a local area or region". Porter argues that economic activities are embedded in social 
activities that social glue binds clusters together. This was supported by recent research showing that particularly in regional and rural areas, significantly more innovation takes place in communities which have stronger inter-personal networks.

Industrial cluster as a kind of enterprise network exists widely in the world. There are some of famous industrial clusters in the world such as microelectronics, biotechnology and venture capital clusters in silicon valley US, chemical, financial and telecommunication media clusters in Frankfurt Germany. In China, industrial clusters are mainly located in three major economic zones Yangtze river delta region, the Pearl river delta and Beijing-Tianjin area. It was estimated that industrial cluster in China accounted for about $22 \%$ of national GDP, about $46 \%$ of FDI, and about $60 \%$ of exports and generated in excess of 30 million jobs (2007). In Zhejiang province, the proportion of industrial cluster output was over $60.9 \%$ in the total output (2014).

Now, some researches show that the essence of an industrial cluster is tightly related to the supply chain. Li Ji-Zi, et al. coupled the industrial clusters and supply chains, and first put forward the concept of cluster supply chain [2]. Cluster supply chain network is a special kind of enterprise network with double feature of cluster and supply chain, with horizontal clusters and vertical chains in its network topology. J. Li et al. (2012) provide a framework and approach to design cluster supply chain without across-chain horizontal cooperation [3]. B. Huang, X. Xue (2012) made an enterprise case study through integrating the advantages of supply chain and industrial cluster [4]. More and more scholars found the inseparate relation between the clusters and supply chains, and paid attention to their coupling. The research of cluster supply chains becomes a new direction and hotspot of the industrial cluster theory. The past decade witnessed the arising of many small and median sized enterprises of clusters in eastern China who participated in the growing economy of supply chain. Cluster supply chain becomes an important channel for enterprises close to the knowledge, resources, markets, and technologies.

\section{The Concept and Features of Cluster Supply Chain}

\subsection{The Concept of Cluster Supply Chain}

Industrial cluster originates from Alfred Marshall's "Principles of Economics" (1890). Industrial clusters are groups of similar and related firms in a defined geographic area that share common markets, technologies, worker skills, and which are often linked by buyer-seller relationships. Supply chain originates from Michael Porter's value chain theory (1980). Supply chain is a system of organizations, people, activities, information, and resources involved in moving a product or service from supplier to customer. Cluster supply chain (CSC) is the combination of industrial cluster and supply chain. In a particular cluster region, there are many research institutions, suppliers, manufacturers, wholesalers and retailers around the same industry or related industry in different segments of the value chain, with a customer-supplier relationship, through the "trust and commitment" informal or formal contract are connected to form local integration of Supply Chain. Cluster supply chain is a complex network composed of those main 
participants.

Enterprises. All kinds of enterprises in the supply chain, including material suppliers, components suppliers, manufacturers, distributors (customers), are the most dynamic members of the cluster supply chain network and determine the innovation performance of the whole cluster.

Government agencies. They are leaders of external business environment of cluster. Government agencies play important roles in market order maintenance, industrial policy guidance, innovation environment and public information platform construction although they are not involved in the cluster supply chain specific business activities.

Academic institutes. Some universities and research institutions are important knowledge and innovative source in cluster supply chain network and important nodes of knowledge and information flow, promote knowledge, information, technology and other resources dissemination and diffusion in the cluster supply chain network.

Intermediaries. External service providers of enterprise production and business which mainly to provide professional technology, skills and information services, including industry associations, technology promotion center, information consultancy, asset evaluation and credit rating agencies, and relevant legal and financial services.

Financial institutions. Organizations to provide business and innovation necessary funding, including commercial banking organization, innovation funds, guarantee institutions, securities markets.

Figure 1 shows the structure and components of cluster supply chain. Cluster supply chain consists of two parts, supply chain enterprises and related organizations. Among them, supply chain enterprises are the main body, which are also the focus of the paper.

Supply chain enterprises include material suppliers, components suppliers, manufacturers and distributors from upstream to downstream. Supply chain core enterprises

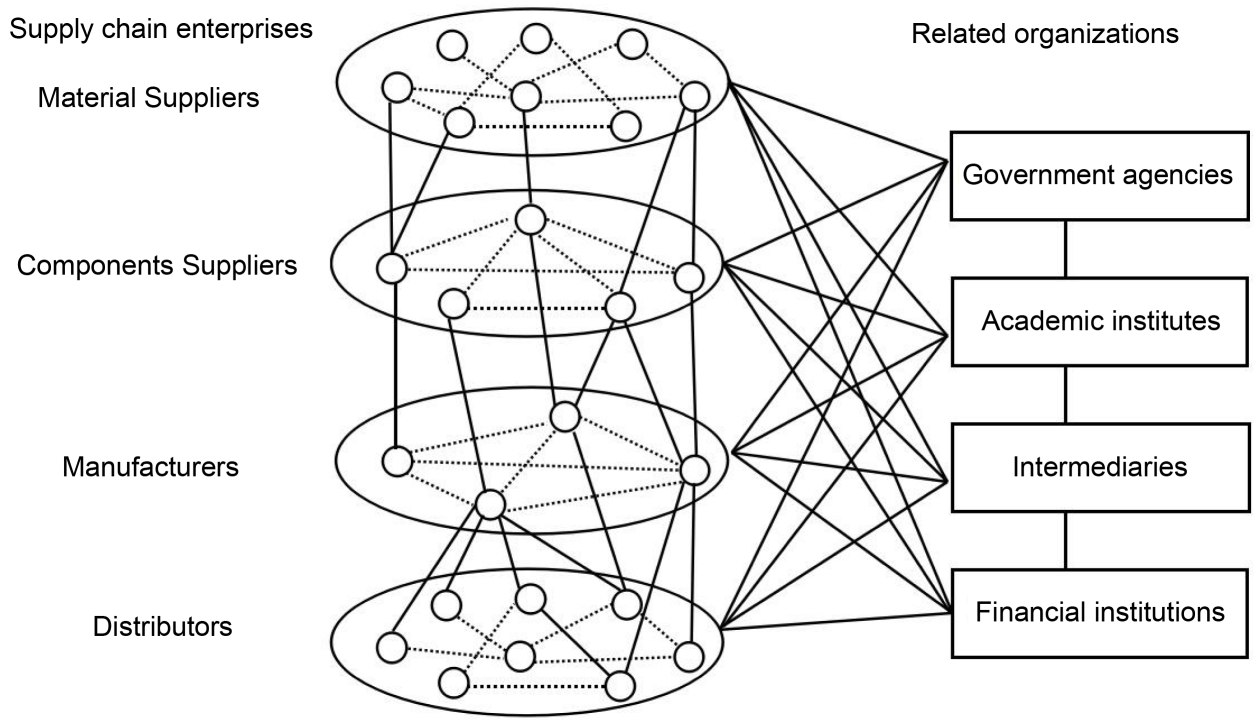

Figure 1. Cluster supply chain structure. 
are the most important organizations in cluster supply chain and determine the structure and operation of the whole cluster supply chain network. There are some different cluster supply chain networks because of different kinds of core enterprises. For example, the core enterprise of Shaoxing textile industrial cluster is a upstream R\&D enterprise. The R\&D enterprise is mainly engaged in the research of new fiber materials, textile engineering, dyeing and finishing technology, textile equipment, information technology etc. It is an important technology source for small and medium enterprises in Shaoxing textile industrial cluster. The core enterprise of Yiwu small commodities industrial cluster is a typical example of market-based type core enterprise which provides a sales platform for the majority of enterprises. More than eighty percent of the enterprises in the cluster can obtain a variety of production and sales resources from the sales platform. The core enterprises of Liushi electrical industrial cluster are several manufacturing enterprises. Figure 2 shows a typical cluster supply chain network that manufacturer $\mathrm{M}$ as core enterprise in Liushi electrical industrial cluster. Liushi electrical industrial cluster is a " 5 kilometers supply circle". There are 455 thousand populations, over 4000 registered firms, 200 large and medium sized enterprises which output is more than 20 million yuan per year, and more than a dozen large enterprise group which output is more than one billion yuan per year within 100 square kilometers of Liushi town.

\subsection{The Features of Cluster Supply Chain}

The template is used to format your paper and style the text. All margins, column widths, line spaces, and text fonts are prescribed; please do not alter them. You may note peculiarities. For example, the head margin in this template measures proportionately more than is customary. This measurement and others are deliberate, using specifications that anticipate your paper as one part of the entire journals, and not as an independent document. Please do not revise any of the current designations.

Social network theory believes that all actors are in the social network and all affected by the structure and relationship of their social network. It is quite different from the assumption that "individual actors do not consider other actors to make decisions and act independently". Social network theory has been introduced into the field of management

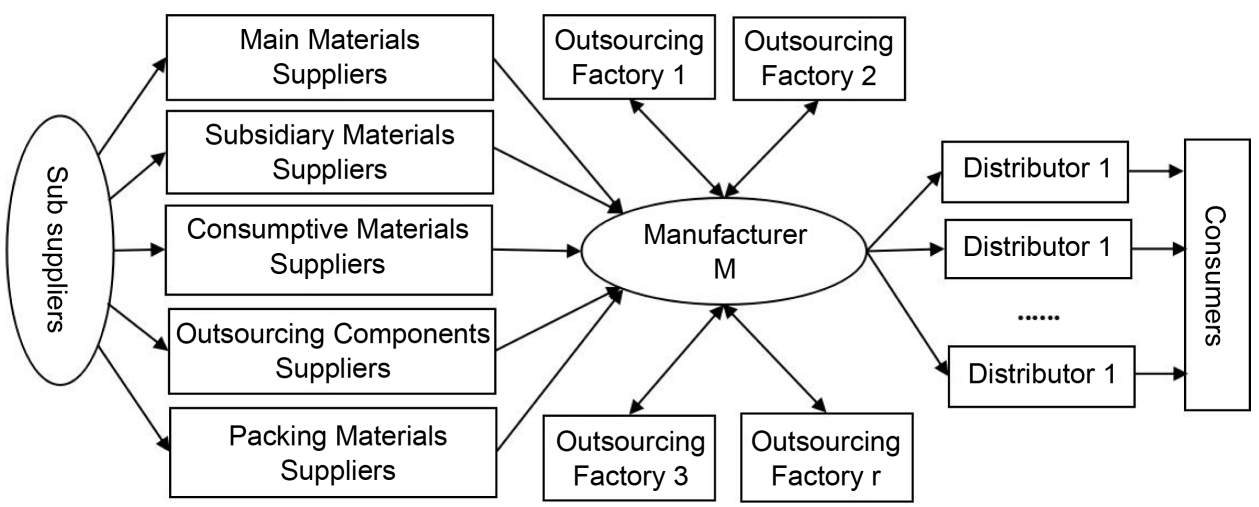

Figure 2. A typical cluster supply chain network that manufacturer $M$ as core enterprise 
research, and it has been widely used in personal and enterprise organizations. The social network can be used to explain information transfer, resource acquisition, knowledge sharing, behavior motivation, competitive advantage, innovation performance and so on. Cluster supply chain has the dual characteristics of industrial cluster and supply chain. T. Qu, D. X. Nie, et al. (2015) proposed a generic cluster supply chain configuration model and an ALC-based decentralized decision model [5]. Cluster supply chain enterprises mostly locate the same industry area and the relationship among members is close and the trust level is high relatively. Cluster supply chain has special network structure and characteristics which are different from general cluster and general supply chain. Enterprises inside cluster supply chain are lower cost than enterprises in cluster when they dealing with suppliers, manufacturers, customers and government agencies, etc. The different characteristics of cluster supply chain and general cluster are shown in Table 1.

For example, specialized suppliers and the accumulation of skilled labor can reduce production factors costs. With relatively low cost and risk, cluster supply chain enterprises enhance their pursuit of technology innovation in order to obtain high profits and achievements. Because of mutual trust, some members of cluster supply chain success of technology innovation will result in the whole cluster supply chain faster response to market changes than outside enterprises. Cluster can generate high levels of innovation and knowledge spillovers. The different characteristics of cluster supply chain and supply chain are shown in Table 2.

\section{The Evolution of Cluster Supply Chain Network}

\subsection{The Type of Cluster Supply Chain Network}

According to the theory of social network analysis, cluster supply chain network is the enterprise relationship network composed of all kinds of members, such as enterprises, government agencies, academic institutes, intermediaries, financial institutions. All of these members constitute the nodes of the network and all the links among these members constitute the edges of the network. Network relationship and network structure of

Table 1. The difference between cluster and CSC.

\begin{tabular}{|c|c|c|}
\hline & Cluster & Cluster supply chain (CSC) \\
\hline Trust & $\begin{array}{l}\text { Non-extended trust based on region and } \\
\text { relations }\end{array}$ & $\begin{array}{l}\text { Can be extended trust based on the common } \\
\text { interests }\end{array}$ \\
\hline Cooperation & Spontaneous and unconscious cooperation & Active and conscious cooperation \\
\hline $\begin{array}{l}\text { Ability } \\
\text { complementation }\end{array}$ & Generally complement each other & Closely complement each other \\
\hline $\begin{array}{l}\text { Organization } \\
\text { degree }\end{array}$ & $\begin{array}{l}\text { Low, loosely organized, high coordination } \\
\text { cost, high information communication cost }\end{array}$ & $\begin{array}{l}\text { High, closely organized, low coordination } \\
\text { cost, low information communication cost }\end{array}$ \\
\hline $\begin{array}{l}\text { Learning } \\
\text { efficiency }\end{array}$ & Low, blindness study, instable organization & $\begin{array}{l}\text { High, specific learning, a clear chain of } \\
\text { upstream and downstream }\end{array}$ \\
\hline $\begin{array}{l}\text { Innovation } \\
\text { performance }\end{array}$ & Low, weak innovation incentives & High, strong innovation incentives \\
\hline
\end{tabular}


Table 2. The difference between SC and CSC.

\begin{tabular}{ccc}
\hline & Supply chain (SC) & Cluster supply chain (CSC) \\
\hline Distance & Far and in different areas & Close and in the same area \\
\hline Relationship & Loose & Close \\
Number of nodes & Less nodes & More nodes \\
Restriction mechanism & Contract & Interdependence and mutual trust \\
Network structure & A single and long chain & Complex network \\
Information transfer & Formal & Informal and formal \\
Information sharing & Low efficient & Quick and efficient \\
External supporting & Obtained from market & Obtained from local \\
External substitution & Low & High \\
Switching costs & High & Low \\
Production flexibility & Low & High \\
Productivity & Low & High \\
Competition type & Inter chain competition & Fierce homogeneous competition \\
\hline
\end{tabular}

enterprise not only affect the quantity and quality of resources that can be obtained by the enterprise but also affect the strategic behavior and strategic execution results of enterprise. Jiang \& Fallah (2009) constructed inventor networks for two telecommuter clusters, New Jersey and Texas and argued that the cluster typology is a key factor determining the structure of the inventor networks in a geographical cluster. With the economic and social conditions of a cluster change, the regional inventor networks change their performance accordingly. Importantly, the cluster typology may be a significant moderating factor for the relationship between the inventor network performance and the cluster development [6].

In the past, many scholars have classified the cluster from the structure of cluster. The most typical is that Markusen (1996) divided cluster into four categories [7]. First, Marshallian cluster which refers Italian cluster mainly consists of medium and small enterprises. Second, hub-and-spoke cluster which consists of many small and medium enterprises around one or more core enterprises. Third, satellite platform cluster which is mainly composed of the branches of multinational corporations. Fourth, state-anchored cluster which is centered on the state-owned enterprises or industries. According to the openness of cluster, the cluster can be divided into closed type, relatively open type and open type. According to the classification of value chain, the cluster can be divided into productive knowledge clusters, technological knowledge clusters and market knowledge clusters. From the two dimensions of homogeneous or heterogeneous, dense or sparse, Davis, et al. (2003) proposes four enterprises network types: dense homogeneous network, sparse homogeneous network, dense heterogeneous network and sparse heterogeneous network [8].

The following discusses the types of cluster supply chain network ties from two di- 
mensions of the network relationship and network structure. Cluster supply chain network can be divided into four kinds of network type, weak tie-sparse type, weak tie-dense type, strong tie-sparse type and strong tie-dense type. Figure 3 shows four kinds of cluster supply chain network type.

Weak tie-sparse type network refers that the majority of cluster supply chain network members are relatively sparse and links among these members are mainly weak ties. In the early development of the supply chain cluster, some enterprises producing the same or similar products gather together and establish simple supply chain relationships because raw materials and intermediate products are difficult to obtain, the relevant support industry of local cluster region or neighboring regions are not sound. Due to lack of support of the upstream R\&D and downstream marketing and other supporting services, cluster supply chain network has not formed a complete industrial support system, the vertical and horizontal co-operations between enterprises are relatively insufficient. The overall characteristics of the network are small amount of members, incomplete member types and less interconnected. Weak tie is the main and the network has not yet emerged with several dense core enterprises.

Weak tie-dense type network refers that the majority of cluster supply chain network members are relatively dense and links among these members are mainly weak ties. Multiple supply chains that produces the same or similar products mixed together to form complex cluster supply chain network. As more and more enterprises, academic institutes, intermediaries to join, the scale of cluster supply chain network has grown. The connections among the members of the network have become denser. The code of behavior of members has been gradually established [9]. The flows in the network are not only a kind of products and material but also information, knowledge and technology. All of these provide the objective conditions for cluster supply chain enterprises innovation.

Strong tie-sparse type network refers that the majority of cluster supply chain network members are relatively sparse and links among these members are mainly strong ties. With the development of the cluster, the relationships among enterprises in cluster supply chain transformed gradually from the weak ties to strong ties. For example, the central position of the core enterprise cluster supply chain is gradually outstanding, the strength of the enterprises promote quickly, the market influence of enterprises expand

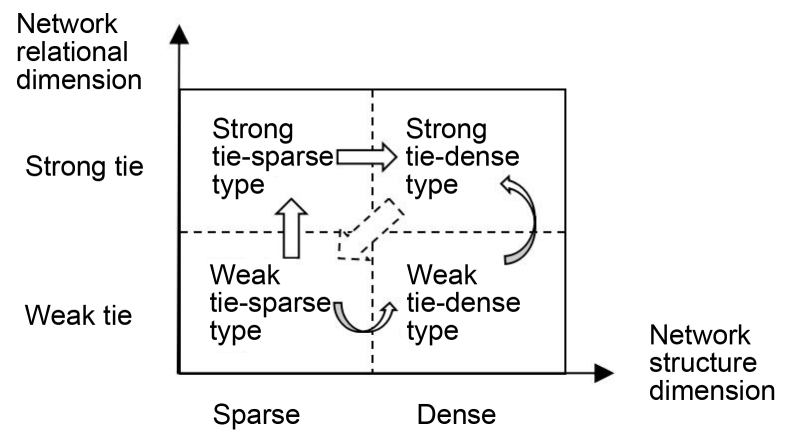

Figure 3. Type and evolution of cluster supply chain network. 
quickly. The raw materials or parts suppliers involved in making production planning of core enterprises. The relationships between the core enterprises and the suppliers become more stable and strong ties are formed. From the point of view of network, cluster supply chain network node members began to diversify at this time. The relationship between enterprises is gradually strengthened. Around the core enterprise there are more strong ties between the vertical enterprise members.

Strong tie-dense type network refers that the majority of cluster supply chain network members are relatively dense and links among these members are mainly strong ties. After further development cluster supply chain network has formed a relatively complete product supply, production and distribution system, network structure and network relationship become mature and stable. The system of division of labor and cooperation of cluster supply chain enterprises is relatively perfect. Core members of cluster supply chain network focus on their core competencies, such as R\&D design, product assembly and so on. Core enterprises have formed their own stable and multilevel supplier network.

In addition, the connections between other related members of the cluster supply chain network and the enterprise members become closer. Academic institutions become important source of innovation knowledge and innovative technology. Intermediaries are collection points of all kinds of information, knowledge and technology and help enterprises to acquire the latest knowledge and technology from the inside and outside of the cluster network. Government agencies develop a variety of policies to encourage and guide technological innovation and provide support to enterprise innovation activities and innovation achievements. Financial institutions provide multi-channel financial support for innovative product development and industrialization. In a short, from the perspective of the network, the connections of all kinds of members in the cluster supply chain network are dense at this time. It is possible to form a number of central nodes. The strong ties ratio of these network connections is high, which is particularly reflected in the connections between enterprise and enterprise, in addition to other enterprises and other related organizations are relatively close. Table 3 shows the difference between the four types. Of course, sometimes the division is not clear boundaries. It is difficult to distinguish strictly.

Table 3. The difference among four types.

\begin{tabular}{ccccc}
\hline & $\begin{array}{c}\text { Weak tie-sparse } \\
\text { type }\end{array}$ & $\begin{array}{c}\text { Weak tie-dense } \\
\text { type }\end{array}$ & $\begin{array}{c}\text { Strong tie-sparse } \\
\text { type }\end{array}$ & $\begin{array}{c}\text { Strong tie-dense } \\
\text { type }\end{array}$ \\
\hline Number of the enterprise & Small & Large & Small & Large \\
Types of organization & Few & Many & Few & Many \\
Homogeneous competition & Gentle & Fierce & Gentle & Fierce \\
Knowledge exchange & Infrequent & Infrequent & Frequent & Frequent \\
Level of cooperation & Low & Low & High & High \\
Network structure & Unstable & Unstable & Stable & Stable \\
\hline
\end{tabular}




\subsection{The Evolution of Cluster Supply Chain Network}

The equations are an exception to the prescribed specifications of this template. You will need to determine whether or not your equation should be typed using either the Times New Roman or the Symbol font (please no other font). Equations should be edited by Mathtype, not in text or graphic versions. You are suggested to use Mathtype 6.0 (or above version). Figure 3 shows the four typical types of cluster supply chain network model and evolutionary process among all of types. It indicates different development stages and different evolution direction of the cluster supply chain network.

First, cluster supply chain network will change from weak tie-sparse type to weak tie-dense type or strong ties-sparse type. In general, the early cluster supply chain network showed weak tie-sparse type. With the increase of network scale and the strength of tie, it may appear weak tie-dense type if the expansion of the scale of relatively more rapidly or strong tie-sparse type if the expansion of the tie strength more rapidly.

Second, cluster supply chain network will change from weak tie-dense type or strong tie-sparse type to strong ties-dense type. With the increase of the network scale and the strength of tie, cluster supply chain network could be represented as stable strong tie-dense type. Bae \& Koo (2008) studied the effects of different network type on the knowledge flow in the enterprise network through agent-based simulation [10]. For individuals, weak tie-dense type network is more conducive to the individual to obtain valuable information and knowledge if loss of information is limited in the process of transmission and the cost of maintaining strong ties is higher. For organizations, strong tie-sparse type network is more conducive to the transfer of knowledge between enterprises through social relations. No matter what evolution path, both of weak tie-dense type and strong tie-sparse type network have more advantage in the flow and sharing of resources than weak tie-sparse type cluster supply chain network.

With the further increase of the network size and the connection strength, the cluster supply chain networks show a stable strong tie-dense type structure. At this point, it is favorable to resources flow and sharing in enterprise network from tie strength and tie density. The last stage, strong tie-dense type cluster supply chain network maybe collapses because of too intense competition or lack of innovation. Network members are closely linked so that most members of the network can get benefits from internal knowledge and technology spillovers. At the same time, a large number of free riding behaviors in the network will seriously damage the members innovation enthusiasm. Moreover, it is easy to form a closed and single information circle in strong tie-dense type cluster supply chain network. Enterprises has reduced external communication channels and lagged behind the external market changes. Innovation ability of the whole cluster supply chain network is limited that maybe lead to the path dependence and regional locking effect. Internal redundant information is more and more, external innovation knowledge is less and less, the network gradually become rigid and can not produce innovative technology and product. If this situation lasts for a long time, cluster supply chain network will lose competitive advantage and enter recession.

At this stage cluster supply chain network has a serious overcapacity and homoge- 
neous competition among members becomes increasingly fierce. Due to excessive competition cluster supply chain organization advantage becomes organization disadvantage. The overlapping of market and technology at the same cluster makes enterprises development space to be squeezed. Enterprises are forced to develop outside the cluster and the original division of labor cooperation system will gradually disintegrate. From the point of view of network structure and network relationship, the nodes in the network are reduced greatly, mutual ties among members become sparse, ties strength are reduced, and the network is isolated into a plurality of parts which are not connected. It perhaps lead to the disintegration of the cluster supply chain network or the reconstruction of the new cluster supply chain network.

Table 4 shows the the evolution of electrical industrial cluster in Liushi town. There were 54 electrical enterprises at Liushi town electrical industrial cluster in 1980. After decades of years' development, the number of electrical enterprises was more than 10,130 by 1994 . The competition among enterprises in the cluster becomes very fierce. Subsequently, small and medium enterprises of Liushi town cluster supply chain carried out constant merger and reorganization and many small enterprises joined to core enterprise to form enterprise group. The number of enterprises reduced to 5200 in 2007. By 2013 the number of enterprises was only about 4000, less than half of the number of enterprises in 1994. However, the output value of electrical industrial cluster in Liushi town had increased from $\$ 0.21$ billion in 1994 to $\$ 8.97$ billion in 2013. Because of the rising costs and lack of innovation, a lot of cluster supply chain networks are declining, many small family factory have closed down. Cluster supply chain network is facing a big change.

\section{Summary and Conclusions}

Knowledge and knowledge management are important sources of competitive advantage in the 21st century. With intense changing market environment, it is a kind of important factors to decide whether the enterprise continues success how to seek knowledge and ability and translate them into practical innovation capability and profitability from the enterprise external. Cluster supply chain is a new type of enterprise network organization forms. With the deepening of its research, the management theory has rapidly developed. Some researchers found that there is a strong relation between industrial clusters and supply chains. In the cluster, always there are a large number of various forms of product or service supply chain. American researcher DeWitt (2006) drew a conclusion that a cluster can be regarded as the geographical centralism of the supply chain by empirical analysis on a furniture industrial cluster in US

Table 4. The evolution of electrical industrial cluster in Liushi town.

\begin{tabular}{cccccc}
\hline Year & 1980 & 1984 & 1994 & 2007 & 2013 \\
\hline Number of the enterprise & 54 & 1000 & 10,130 & 5200 & 4000 \\
Value of output (billion \$) & -- & -- & 0.21 & 4.69 & 8.97 \\
\hline
\end{tabular}


[11]. C. Panmanee (2016) analyzed the practices of Arabica coffee growers in Pang Ma$\mathrm{O}$ and Pamiang villages for planning and developing green cluster supply chains [12].

Cluster supply chain is a kind of complex enterprise network which is mainly composed of enterprises, government agencies, academic institutes, intermediaries and financial institutions. Compared with enterprises in the cluster, the enterprises in cluster supply chain have more close common interests and cooperation, higher organizational level and higher learning efficiency. Compared with enterprises in the supply chain, the enterprises in cluster supply chain have more complex local cooperation network, more informal information exchange, lower production cost, higher external substitution and more intense homogeneous competition. Cluster is the regional carrier of cluster supply chain, which determines the composition of cluster supply chain and restricts the connection type of cluster supply chain network. According to structural dimension and relational dimension of social network analysis theory, cluster supply chain network can be divided into four basic tie type of cluster supply chain network: sparseweak tie, intensive-weak tie, sparse-strong tie and intensive-strong tie. The study analyzes characteristics of four tie types and the influence of enterprise knowledge transfer, and points out mutual evolution rule of different types. The results of study show that network of cluster supply chain developments to relative mature period, the links between the members of the network will be relatively dense, coupling relationship will be relatively strong within the network, information and knowledge within the network will be flow smoothly. The study also shows that intensive-strong tie network maybe appears negative effect of network innovation locked when developing to late, and eventually leads to cluster supply chain network disintegration and reconstruction.

The paper focuses on the study of concept, features and evolution of cluster supply chain network. Affected by external and internal environment, the cluster supply chain network is constantly evolving, from generation to development and growth, and then to differentiation and reorganization. In fact, cluster supply chain network is also open network. The communication and interaction between cluster supply chain network and external enterprise networks is one of the valuable research directions in the future. It will be an important research direction to study the openness and externality of the cluster supply chain network from the empirical perspective.

\section{References}

[1] Porter, M. (1998) Clusters and the New Economics of Competition. Harvard Business Review, 6, 77-91.

[2] Li, J.Z. and Cai, G.N. (2004) Study on the Frame of Supply Chain System Based on Cluster. Science Research Management, 3, 77-82.

[3] Li, J., et al. (2012) Intelligent Model Design of Cluster Supply Chain with Horizontal Cooperation. Journal of Intelligent Manufacturing, 4, 1-15.

[4] Huang, B. and Xue, X. (2012) An Application Analysis of Cluster Supply Chain: A Case Study of JCH. Kybernetes, 2, 254-280. http://dx.doi.org/10.1108/03684921211213070

[5] Qu, T., Nie, D.X., et al. (2015) A Newly Emerged Multidisciplinary Optimization Method: Augmented Lagrangian Coordination (ALC). Computers \& Industrial Engineering, C, 43- 


\section{5. http://dx.doi.org/10.1016/j.cie.2014.12.026}

[6] He, J. and Fallah, M.H. (2009) Is Inventor Network Structure a Predictor of Cluster Evolution? Technological Forecasting and Social Change, 1, 1-106.

http://dx.doi.org/10.1016/j.techfore.2008.03.020

[7] Markusen, A. (1996) Sticky Places in Slippery Space: A Typology of Industrial Districts. Economic Geography, 3, 293-313. http://dx.doi.org/10.2307/144402

[8] Davis, G.F., Yoo, M. and Baker, W.E. (2003) The Small World of the American Corporate Elite. Strategic Organization, 3, 301-326. http://dx.doi.org/10.1177/14761270030013002

[9] Coleman, J.S. (1990) Foundations of Social Theory. Harvard University Press, Cambridge.

[10] Bae, J. and Koo, J. (2008) Information Loss, Knowledge Transfer Cost and the Value of Social Relations. Strategic Organization, 3, 227-258.

http://dx.doi.org/10.1177/1476127008093518

[11] DeWitt, T., Giunipero, L.C. and Melton, H.L. (2006) Clusters and Supply Chain Management: The Amish Experience. International Journal of Physical Distribution and Logistics Management, 4, 289-308. http://dx.doi.org/10.1108/09600030610672055

[12] Panmanee, C. and Wiboonpongse, A. (2016) Determinants of Green Cluster Supply Chain Adoption and Practice of Arabica Coffee Growers in Pang Ma-O and Pamiang Areas. International Journal of Intelligent Technologies \& Applied Statistics, 2, 169-189.

\section{Submit or recommend next manuscript to SCIRP and we will provide best service for you:}

Accepting pre-submission inquiries through Email, Facebook, LinkedIn, Twitter, etc.

A wide selection of journals (inclusive of 9 subjects, more than 200 journals)

Providing 24-hour high-quality service

User-friendly online submission system

Fair and swift peer-review system

Efficient typesetting and proofreading procedure

Display of the result of downloads and visits, as well as the number of cited articles

Maximum dissemination of your research work

Submit your manuscript at: http://papersubmission.scirp.org/

Or contact ojbm@scirp.org 